\title{
FELICIDAD Y POIESIS EN LA NARRATIVA DE CLARA OBLIGADO: MODELO PARA ARMAR
}

\author{
HAPPINESS AND POIESIS IN CLARA OBLIGADO'S NARRATIVE: MODEL KIT
}

Begoña ALONSO MONEDERO

Universidad de Burgos

Resumen: La obra narrativa de Clara Obligado tiene su origen en su exilio de Argentina en 1976, una circunstancia que impulsa su labor poética hacia una escritura excéntrica y de frontera, en la frontera de los géneros y en la frontera del idioma. En La muerte juega a los dados, el lector puede encontrar no solo un conjunto de cuentos rico en voces y estilos narrativos diversos sino también la experimentación de un género nuevo, pues en la lectura se construye una forma de novela ramificada que surge en la sintaxis de los cuentos, al modo de los laberintos borgianos. Los destinos de los personajes, dentro de un caos aparente, van formando un modelo fractal de gran belleza y emoción poéticas, en que cada detalle sirve a un orden de conjunto y puede cambiar su signo. Entre la fatalidad y el azar, aparece representada la utilidad de la escritura como un destino posible de felicidad.

Palabras clave: exilio; escritura excéntrica; género híbrido; laberinto borgiano; novela ramificada; jardín; felicidad.

Abstract: Clara Obligado's narrative work has its origins in her exile in Argentine, back in 1976. This circumstance drives her poetic activity into an eccentric and border writing, in both genders' and language's border. In La muerte juega a los dados, the reader will find not only a set of tales rich in voices and diverse narrative styles but also the experimentation of a new gender. This is so because a form of branched novel, arising in the tales' syntax — as Borgian's labyrinth—, is built along the reading. The characters' fates make up a fractal model full of beauty and poetic emotion in which every detail is part of an assembly that can change its whole meaning; and all of it despite the apparent chaos. Between fate and chance, the writing utility is represented as a potential happy destiny.

Key words: exile; eccentric writing; hybrid gender; Borgian's labyrinth; branched novel; garden; happiness. 
Pues qué ¿es preciso para que las cosas sean útiles que sean prosaicas? ¿Quién se atreverá a negar la utilidad soberana de lo soberanamente bello?

María de la O Lejárraga

Q uizá sea posible aceptar, sin demasiada objeción, la afirmación de que no es fácil al oficio de escritor representar la felicidad y de que, si bien muchos lo han intentado, casi ninguno lo ha conseguido, como pensaba Jorge Luis Borges. «La finalidad permanente de la literatura es la presentación de destinos» declaraba en «La felicidad escrita», pero

[...] la presentación de una dicha, de un destino que se realiza en felicidad, es tal vez el goce más raro (en las dos significaciones de la palabra: en la de inusual y en la de valioso) que puede suministrarnos el arte. [...] Parece desalentador afirmar que la felicidad no es menos huidiza en los libros que en el vivir, pero mi observación lo comprueba (1994: 41).

Representar la felicidad como una de las múltiples posibilidades del destino, o del azar, en una literatura que tiene su origen en la experiencia del exilio -como es la de la escritora Clara Obligado- y en la pérdida irreparable de la tierra, de la familia, del idioma..., no deja de ser algo todavía más extraño o sorprendente. De forma que indagar en qué medida está vigente el paradigma clásico que confiere utilidad a la belleza ${ }^{1}$ puede alcanzar casi un valor subversivo, acostumbrados, como hemos estado durante tanto tiempo, a reivindicar una obra de arte o una belleza que han de ser inútiles, o «de un interés desinteresado», por decirlo en términos kantianos. Utilidad y belleza son nociones que no muy a menudo transitan juntas $\mathrm{y}$, sin embargo, como veremos, comprometidas en la narrativa excéntrica y trasterrada de la escritora Clara Obligado, afincada en España desde que se salió al exilio en 1976, cuando era una estudiante universitaria de literatura y discípula de Jorge Luis Borges. El aliento poético del maestro puede reconocerse en la preferencia de ambos por las formas narrativas breves, pues ambos elogian la complejidad que puede alcanzar el cuento o el relato frente a la novela ${ }^{2}$, géneros que ofrecen más ricas posibilidades creativas y exigen una mayor implicación por parte del lector, pero también en un concepto de literatura comprehensivo y abarcador de distintos universos.

\footnotetext{
${ }^{1}$ La vigencia de la noción de felicidad personal y social de la literatura es uno de los objetivos del Proyecto FELITER (Felicidad y Literatura) inscrito en el Instituto de Estudios Medievales y Renacentistas y Humanidades Digitales de la Universidad de Salamanca; en el marco de ese proyecto se celebró el coloquio «Felicidad y LiteraturaS», los días 12 y 13 de enero de 2017 en el Colegio Arzobispo Fonseca (Universidad de Salamanca), en el que se presentó una primera versión de este trabajo.

2 «Me han preguntado por qué nunca he intentado escribir una novela. La pereza, por supuesto, es la primera explicación. Pero hay otra. Nunca he leído una novela sin cierta sensación de aburrimiento. Las novelas incluyen material de relleno; creo, por lo que sé, que el material de relleno puede ser una parte esencial en la novela. Pero he leído y vuelvo a leer una y otra vez muchos relatos breves. Entiendo que en un relato breve de, por ejemplo, Henry James o Rudyard Kipling podemos encontrar tanta complejidad -y de un modo más agradable- como en una larga novela». (Borges, 2005: 141)
} 
En uno de sus cuentos, «Exilio» (último de la serie de Las otras vidas, 2005), relata con técnica autoficcional este punto de partida, este viaje a lo desconocido, e imagina en una estructura iterativa y en abismo las otras vidas posibles, los posibles encuentros y cruces de caminos en que quedaba expuesto el destino del exiliado: «Salí vestida de verano, como si fuera una turista que se dirige a las playas del Uruguay y, dos o tres días más tarde, subí al avión que me llevaría a España, donde era invierno. [...]». Y más adelante, reiniciándose el relato con variaciones, vuelve de nuevo al mismo punto de partida: «El 5 de diciembre de 1976 llegué a Madrid aterida de frío. Venía del verano, la tristeza y la falta de sol fueron el primer impacto. [...]» $(2005: 117)^{3}$. La experiencia del exilio es, sin duda, el desencadenante de su escritura, el punto de origen de su viaje literario, y toda su obra se ve traspasada por la experiencia del trasterrado, por esa dolorosa ruptura con el tiempo y el espacio, que fragmenta toda la realidad y los destinos, y hace imposible el retorno, incluso después del regreso (el destiempo que decía Mario Benedetti), como ella misma confiesa: «Vuelvo a mi país de origen casi todos los años. Soy una extranjera, una persona que se siente bien y mal en dos lugares. Pero esto creo que es muy bueno para la escritura, que siempre pide un poco de distancia». (Obligado, 2015b) ¿Cómo afrontar el destino de una vida feliz desde el destierro, cuando uno parece quedarse a la intemperie, sin el proyecto de una vida? ¿Cómo sentir la propia vida y las de los otros cuando los destinos se truncan? Clara Obligado ha confesado en alguna entrevista:

En el exilio, que nunca es dorado, hay muchas vidas larvadas, mutiladas, vidas que no se dieron. Ya lo dijo Borges: «Los hechos graves están fuera del tiempo». Así que siempre voy a ser una exiliada. También soy Tauro, y, por lo tanto, vengativa: nos han echado y no olvido. Pero al final no pudieron. Además, la mejor forma de combatir la dictadura es ser feliz (Obligado 2006).

Ni el tiempo ni el espacio vuelven a ser los mismos tras una experiencia tan radical y el trayecto que nos une a un destino feliz — sea cual sea el significado de este sintagma - no parece ser un camino recto e inequívoco con la guía de la virtud, como en épocas clásicas. Según podemos leer en el diálogo de Séneca «Sobre la felicidad»:

Una vez emprendido el trayecto, siempre y cuando sea recto, debemos apreciar cuánto se consigue cada día, y cuanto mayor es la proximidad a aquello a lo que nos empuja un deseo natural. Ciertamente, todo el tiempo que andamos dando vueltas de un lado para otro, no tras de un guía sino tras del griterío y el clamor disonante de quienes nos llaman en direcciones opuestas, la vida se desgasta entre divagaciones, breve aunque nos esforcemos en mejorar día y noche. De modo que hay que decidir a dónde nos dirigimos y por dónde, no sin contar con un especialista a quien le sean conocidos los lugares a los que nos dirigimos; y es que, evidentemente, la situación en este caso no es la misma que en el resto de los viajes. En éstos, unos senderos bien trazados y los habitantes del lugar a quienes se pregunta no permiten equivocarse, en cambio, en aquel caso, cuanto más pisoteado y frecuentado es el camino, más engaña (Séneca, 1986: 226-27).

¿Cómo podría decidir la dirección de su destino el desplazado, el desterrado, el que deja de estar... sometido a los vaivenes del azar? ¿Cómo asimilar la ruptura con un lugar, con un pasado, con un idioma cuando no hay «senderos bien trazados» sino caminos que se bifurcan? En este sentido, la narrativa de Clara Obligado muestra, en una posición anticlásica, o al menos contraria a la de Séneca,

\footnotetext{
${ }^{3}$ De las técnicas metaficcionales, como la recursividad o la puesta en abismo, aplicadas por Clara Obligado en este relato de «Exilio», me ocupé en otro trabajo (Alonso, 2011).
} 
una aspiración a la vida feliz que no traza una línea recta, ni tiene un guía, sino que, como hace la naturaleza de forma aparentemente azarosa, como las estalactitas excéntricas, incluye desvíos, cambios de dirección, errores y rectificaciones, que surgen del cruce con las trayectorias y destinos de los otros. $\mathrm{Su}$ narrativa asume una forma poética con vocación por lo «marginal» $\mathrm{y}$ «excéntrico», innovadora en el fondo y en la forma, que vuelve la mirada hacia lo pequeño, lo ignorado, lo distante, y lo rescata para la poesía.

\section{Una escritura híbrida y excéntrica}

Su condición de extranjera, deliberadamente asumida como una identidad, sin duda, deja una profunda huella en sus narraciones en el interés que muestra por los desplazados, pero, sobre todo, en el punto de vista desde el que mira la realidad que está en los márgenes, focalizando en ella los aspectos más invisibles. Al fondo de sus relatos encontramos pequeñas alusiones que, para el lector atento, desvelan hechos atroces, hechos históricos a menudo ignorados por la historia, o los lugares más distantes del centro del foco de interés, los más fronterizos ${ }^{4}$, donde en cada relato la realidad se quiebra en diversas geografías, en voces narrativas, en espacios, animales y objetos..., derramándose en fragmentos que van reconfigurando nuevas formas fractales, que aspiran, sin embargo, a su unidad en una extraña belleza.

Esta forma de escritura «excéntrica» se consagra en tres de sus últimas obras. La primera, Las otras vidas (2005), a la que pertenece el cuento de «Exilio» ya mencionado, en que el mecanismo autoficcional permite desdoblar el yo ficticio en distintos yoes, cambiantes, simétricos... aplacando quizá así en la reescritura la sensación de un destino doloroso, también desdoblando la identidad, o multiplicándola en otras vidas, o sugiriendo que a la felicidad quizá pueda llegarse por bifurcaciones o caminos secundarios. El siguiente, El libro de los viajes equivocados (2011), con sus cruces de trenes y trayectorias tangentes en un vasto recorrido en el tiempo y en el espacio, parece defender también la idea de que los destinos inesperados pueden llegar a describir un paisaje global luminoso, esa «espiral admirable» (spira mirabilis) de belleza, como la curva de la caracola, en que se inscriben los relatos de esta obra; una espiral logarítmica en que la curva es cada vez más amplia y creciente en su constante cambio y renacimiento, que desborda el propio cuerpo textual de la obra. Los paratextos que lo enmarcan revelan el esmero de Obligado por encauzar la experiencia de la lectura en ese viaje; así en la apertura:

Comencé a escribir este libro en mi libro anterior, cuando me preguntaba por el sentido del destierro. Años más tarde, me encontré pensando en las proyecciones de la diáspora en la vida de quienes la emprenden. En este momento de crisis, el viaje vuelve a sugerirme el retorno de otras épocas y de ciertas ideas que imaginaba, por fin, extinguidas. Este ir y venir, esta espiral, es la historia de mis cuentos. Solo me gustaría proponer a quienes los lean que lo hagan en el orden en el que aparecen, ya que esconden un texto más amplio, que necesita de este recorrido (2011a: 13).

\footnotetext{
${ }^{4}$ «Somos escritores de frontera, y el mundo de hoy es un mundo de frontera. El capital, por ejemplo, no tiene país. Sin embargo, en literatura todavía estamos atados por los nacionalismos», dice en una entrevista a El Cultural, del 29 de abril de 2015 .
} 
Y cerrando, como colofón, sitúa una magnífica espiral logarítmica, imagen del viaje en el tiempo y en el espacio que materializa la escritura en esa narrativa de signo creciente.

La belleza intelectual que presentan algunos conceptos abstractos como el infinito, el centro o el límite ha atraído a los escritores. En particular, para el caso de Jorge Luis Borges, Stephanie Alcantar afirma: «El trabajo creativo que Borges lleva a cabo funge con la tarea de ofrecer al lector un nuevo signo sugerido del híbrido matemáticas-literatura, donde la potencia del nuevo significado del concepto colabora en la concepción de una experiencia inédita en el lector.» (2017: 15). El diseño o figuración de la espiral logarítmica narrativa de Los viajes equivocados participa de esa misma hibridación de literatura y matemáticas, persigue con determinación una imagen poética de la literatura que no oculta su filiación borgiana, sino que aspira a integrar en un mismo movimiento ciencia e imaginación, verdad y poesía, con la ayuda siempre del lector. Dice su autora de forma nítida:

Mi libro es esa espiral logarítmica que hemos nombrado al principio. Una espiral basada en el número áureo, base del Arte a partir del Renacimiento. ¿Por qué nos conmueve algo que ya está dibujado en el vuelo de los pájaros, en los ombligos y en los giros del contenido de una olla cuando le damos vueltas? Lo bello y lo natural se tocan (Obligado, 2011c).

Este viaje a la belleza también está presente en la tercera de las tres obras mencionadas, La muerte juega a los dados (2015a), con la que culmina hasta ahora la experimentación formal al dar a luz con ella un nuevo género. Un género híbrido también, pues se trata de un libro de relatos que pueden leerse como independientes, pero que, si se leen secuencialmente en el orden propuesto, al modo cortazariano, construyen una novela o la construye el lector con su itinerario. La autora ofrece en el inicio de la obra un camino de lectura bifurcado:

\footnotetext{
Estos cuentos proponen al menos dos itinerarios de lectura: el primero es lineal, y en él se percibirá la trama policíaca y la historia de la familia Lejárrega; el segundo lo puede organizar el lector a voluntad, y en él aparecerán historias que tienen algunos puntos en común. Esta forma mestiza, que lo es también el idioma, es mi manera de plantear una escritura, descolocada, fuera de los límites, extranjera (2015a: 11).
}

De igual manera se enfrentan la representación de diferentes destinos, el azar y la muerte, la búsqueda de la felicidad, y profundiza en las formas narrativas desde la frontera de los espacios y los tiempos, de la historia personal y global, en el continuo ir y venir del presente al pasado, de la propia vida y las otras vidas posibles. Su creación literaria, originada en la experiencia del exilio, pero desprendida de tonos testimoniales o confesionales, se hace fuerte acentuando los aspectos formales, las técnicas narrativas rompedoras, bajo la doble influencia de Borges (el tiempo en el laberinto, el laberinto de la escritura) y de Cortázar (el juego que implica al lector), en pro de un resultado que busca la emoción en lo poiético (si se puede decir así), más que en una referencialidad representada sentimentalmente, en la emoción de quien lee y descubre una realidad latente y periférica por mecanismos indirectos. Las palabras o la forma del relato se interponen como un filtro que ayuda a mirar y a ver, pero obliga a un esfuerzo hermenéutico de cohesión en el lector que amortigua una empatía demasiado directa con lo que se muestra: el lector juega también. 
Así, su escritura «excéntrica» manifiesta una determinada voluntad de renovación en la frontera de los géneros. Entre el cuento y la novela, elige Obligado el cuento, al que considera un género más libre, menos comercial, más independiente: «Es una actividad inútil -dice con toda la ironía- no tiene ningún sentido, por tanto, es un buen terreno de experimentación» (Obligado, 2011b). La experimentación con un género narrativo como el cuento o con sus diversas formas integradas en una forma novelesca sitúa la obra de Clara Obligado en la vanguardia de la narrativa actual. De modo que La muerte juega a los dados, por una parte, puede incluirse entre los cuentarios posmodernos, según los define Francisca Noguerol (2008), como texto de ruptura o «disconforme con la tradición», caracterizados por como «artefactos marcados por la indagación metaficcional, la intertextualidad y la ironía». Pero, además, mientras en estos últimos todavía pueden encontrarse «constantes estructurales como la repetición de un motivo o la adscripción a un determinado género» que actúan como marco narrativo ${ }^{5}$, en el caso de Obligado los motivos de repetición, las simetrías, los juegos especulares, que cohesionan la narración, siendo los mismos cambian en su contexto y, por tanto, exigen continuos cambios de significación por parte del lector; y, por ello, más que servir para una articulación externa o a un marco narrativo, es solo desde la tarea hermenéutica del lector y el proceso de resignificación que opera en ella, solo desde la lectura morosa del detalle como desde la relectura de la globalidad como esos motivos, esos signos, construyen el mundo narrativo y poético. En el fondo, late una aspiración nítida e irrenunciable a la unidad en este «modelo para armar» que es este cuentario-novela de La muerte juega a los dados, que solo se construye en el encuentro con el lector, que va a conectar a modo de hipervínculos, los fragmentos en una realidad rota reconstruida poéticamente.

\section{Una narrativa fractal: la novela ramificada}

En La muerte juega a los dados, donde se enfrenta la escritora a muchos de sus demonios familiares, la milimétrica composición de la obra da cuenta de grandes dosis de precisión y brillantez en una estructura fractal que trata de ofrecer una representación de la vida más ajustada a su realidad, aunque solo apuntemos en este trabajo algún ejemplo. Todo sucede en los intersticios o huecos de indeterminación que dejan las palabras y las historias, y que el lector termina por rellenar en su lectura. El hecho es más meritorio si consideramos que algunos de estos cuentos ya habían sido publicados anteriormente y no hay en entre ellos nexo, ni temporal ni espacial, ni estilísticos (como ocurre en otros cuentarios) pero que conforman una estructura compleja que intenta representar la forma en que compiten en la vida el azar y el destino. De ahí que, desde el título se replica a la famosa frase de Einstein que afirma «Dios no juega a los dados». Para Clara Obligado, «nuestra vida está manejada

\footnotetext{
5 Según Francisca Noguerol, frente a los cuentarios posmodernos, «las colecciones de cuentos integrados modernas presentan unidad espacial, temática y de personajes para ofrecer una visión totalizadora de la realidad, en la que predomina la nostalgia del pasado y la visión de un presente marcado por la alienación»; pone como ejemplo a Ricardo Palma Manuel Mujica Lainez, o Paloma Díaz-Mas, en cuyos cuentarios los espacios de Perú, Buenos Aires o Madrid, conceden un elemento de unidad estructural; o bien el de los cuentos unidos por el tema histórico en que se insertan «anécdotas curiosas protagonizadas por personajes secundarios», o por los personajes de una misma familia o comunidad (2008: 162-172).
} 
por el azar» (2015b), o también es posible que nuestro destino sea cumplir el destino de otros, porque nuestras vidas se cruzan al girar a la manera en que gira el vuelo de un azor o aire en una tormenta.

El relato de conjunto - entretejido por los 18 cuentos que componen la obra-comienza en 1936 con el asesinato del patriarca, Héctor Lejárrega, del primer cuento. Un inicio clásico de novela policíaca a partir del cual se va construyendo una saga familiar con las vidas de las mujeres de tres generaciones (la de Leonora, esposa del patriarca, la de su hija Alma, y las hijas de esta, Sonia y las mellizas, pero no solo las de ellas), cuyos trayectos van ramificándose desde el punto de origen en distintos destinos, en amplios espacios de una geografía y de una historia que componen un mapa más bien pesimista del mundo: un soldado que huye en el París de la ocupación nazi de la segunda Guerra Mundial (ahí está Teo que distrae el miedo mientras hace pajaritas de papel), una pareja recién casada en el trasatlántico del bombardeo del Cap Arcona, una joven víctima de la prostitución en la revolución mejicana en la primera década del Xx, la tortura de la rebelde Sonia en la última dictadura argentina...

Todo ello se despliega en distintos géneros o subgéneros: no solo el policíaco o el de la saga familiar de tres generaciones, la de Leonora, la de su hija Alma, y las hijas de esta (como en Lo que el viento se llevó, cuya fecha sirve para registrar el año de la muerte del patriarca que sitúa el origen de la fábula narrativa); también está el género epistolar (en las cartas de Leonora mintiendo a su madre en su viaje de novios o en las de la escritora a su hermana en último relato); la materia histórica (en «Cosas que me pregunto mientras escribía estos cuentos»); cuentos poéticos y metapoéticos (como «Nada útil», al que volveremos), humorísticos o absurdos («Interferencias», «Paranoias»...) que pueden tocar la realidad más sombría, como el la médium lapona (en «Interferencias»); también lo autobiográfico, mejor diríamos autoficcional, en el último de los relatos «Verano», donde la voz parece encontrar la paz o la verdad personal en su propia narración.

Las voces narrativas alternan la primera con la tercera persona gramatical que se interna en los personajes. El cuento, como unidad narrativa, permite de forma natural construir la narración con variaciones, sin construir una instancia narrativa uniforme, pues la tercera persona mimetiza su voz con cada personaje que entra en juego adoptando su perspectiva y sus giros linguí́sticos en cada caso. Es una narración poliédrica que incluye diálogos, monólogos, estilo indirecto libre, incluso en el mismo cuento. La perspectiva es cambiante y mixta, no centrada. También distintos personajes toman la palabra en primera persona en tono rememorativo: Fernanda que vive en París (pero «que no renuncia a la nostalgia», como en la cita paratextual de García Márquez) en su vuelta a Buenos Aires con su padre; o la española que vuelve a Buenos Aires a buscar a su difunto marido Vicente a través de la médium; o la escritora del último cuento. Posiblemente una primera persona autoficcional con distintos tonos. Pero en cada cuento o en cada capítulo, según se mire, presenta la vuelta atrás de cada rememoración de sus personajes, que evalúan su pasado y lo hacen con más intensidad cuanto más avanza el libro.

Nunca el relato es lineal, cada cuento nos lleva a un tiempo cronológico distinto (que puede ser el de la muerte de Héctor Lejárrega del primer cuento, 1936, o 1927, año del viaje inaugural del Cap Arcona, o 1945 en plena segunda guerra mundial...o a la Polonia de Lech Walesa), un tiempo narrativo 
iterativo en que la historia parece repetirse en sus detalles, en sus pequeños fragmentos, con cierta irregularidad dentro de la repetición, hasta llegar al presente del último cuento; también acudimos a lugares distintos (Buenos Aires, París, Polonia, México...); pero en cada relato se produce siempre un movimiento de progreso hacia atrás, que te devuelve al origen (a la alfombra, al cadáver) o a un punto anterior, aportando en cada revuelta una variación, un cambio de perspectiva, un giro sobre un mismo eje que lleva a otro punto. Todo ello parece tener la apariencia de un caos, pero un caos que tiene un ritmo, un patrón y que también cumple un cierto determinismo o destino.

Las repeticiones se producen como en los fractales por ramificación con autosimilitud, hechos que se repiten con ligeras variaciones ${ }^{6}$. Personajes, lugares, pero especialmente los objetos reaparecen en unos cuentos y en otros cohesionando desde el detalle a pequeña escala la historia que se va tejiendo en todo el volumen. Es una forma de cohesionar las partes fragmentadas mediante la relación anafórica, una técnica que Obligado señala para la elaboración de los hiperbreves y aquí utiliza con gran rendimiento poético (Obligado, 2004). La realidad que aparece caótica y violenta en la primera parte de la obra, gira en su mitad y reconvierte, en la segunda parte, el valor sígnico de las personas, los lugares y los objetos, en perfectas simetrías y autorréplicas: aquella alfombra roja que envolvió el cadáver es la misma en la que jugaban las hermanas como si fuera una balsa, la balsa de Stevenson; el apartamento de cortinas amarillas en el viejo barrio parisino de Le Marais, que escondía el soldado perseguido por los nazis, es después el de la feliz Fernanda; la horquilla que perdió Leonora (que no amaba a su marido) en su viaje de novios a Europa, en el Cap Arcona en 1927, es casualmente encontrada por Irina en el camarote, que sí estaba enamorada del suyo, antes del bombardeo del buque en 1945; las cartas que se cruzan (en la primera parte con mentiras, en la segunda parte, revelando la verdad), la casa, el jardín, la pileta de «Los naranjos», donde se ahoga Viv, donde el miedo de Alma, donde la valentía de Sonia al bañarse... Los objetos van cargándose de nuevos sentidos, resignificándose, con cada nueva aparición en los distintos relatos. Las vidas de los personajes también parecen replicarse en recurrencias especulares: los dos hermanos de Héctor y Diego y sus respectivas mujeres con destinos divergentes; Alma, tratada en la clínica con electrodos y su hija Sonia, torturada en «Las Eléctricas»; las hermanas mellizas de Sonia... Podría decirse que, como ocurre con los hechos bíblicos del Antiguo y Nuevo Testamento, hay una correspondencia de sentido, un significado tipológico, que los pone en relación, según sea el camino tomado en retrospectiva o en perspectiva. Personas, hechos y objetos mestizos, poliédricos, de ninguna parte y de todas, reaparecen azarosamente como en un laberinto (luego ordenado) multiplicando su valor evocador en el lector, al variar el marco, la función o la situación en que aparecen, así como otros elementos que se le yuxtaponen, resemantizándose, o extendiendo su sentido (Barthes: 1993) en una nueva sintaxis reconfiguradora, resemantizándose o resignificándose, en el sentido en que Roland Barthes habla de la significación en

\footnotetext{
${ }^{6}$ Lauro Zavala define la fractalidad como «la idea de que un fragmento no es un detalle, sino un elemento que contiene una totalidad que merece ser descubierta y explorada por su cuenta» (2000); no obstante, en la narrativa de Clara Obligado, el modelo fractal se despliega no solo en el detalle sino también en la visión de la totalidad, a través de los elementos recurrentes que funcionan a modo de hipervínculos, trazando caminos, vasos comunicantes entre cuentos, que terminan componiendo una figura global unitaria que debe ser descubierta y completada por el lector.
} 
su Semántica del objeto, es decir, considerando que en el significado de los objetos no solo se transmiten informaciones, sino también sistemas estructurados de signos, sistemas de diferencias, oposiciones y contrastes (1993: 246).

Es en mitad de la obra donde hallamos el texto clave que constituye el verdadero «atractor» de este caos: «El efecto coliflor», un cuento que contiene toda una teoría literaria desde la que leer este libro de relatos-novela. La situación es bastante cómica; en el espacio familiar de una cocina y ante las ramificaciones fractales de una coliflor seccionada por la mitad, se contraponen, con gran ironía, los puntos de vista de sus dos personajes: la teoría del detective O’Brien para dar con el culpable del crimen (e indagar la verdad en el pasado) y la de su esposa Amalia, que defiende la solución intuitiva de los problemas y cuya mirada se dirige no a la víctima ni al crimen sino a lo que vino después, hacia las vidas de quienes lo sobrevivieron, en una mirada prospectiva y agarrándose a la vida. O’Brien recapacita:

\footnotetext{
Ahí mismo, en calzoncillos y en la cocina, frente a la coliflor partida, había comprendido todo: la estructura del universo, el tejido del cerebro, el camino de los nervios, las venas, el crimen. Sí, se dijo, (...) todo se repite a diferente escala, había atisbado el ojo del universo en una hortaliza, el tallo grueso que se separaba en conglomerados idénticos hasta formar una cabezota semejante a una nueve. Y así, hasta el infinito. ¡El plano de todo lo creado! Solo había que desandar el camino, atravesar la masa confusa de ramificaciones idénticas y regresar al tronco principal, si desandaba el camino llegaría a la verdad. O sea, la solución del asesinato de Héctor Lejárrega (124).
}

«Si desandaba el camino llegaría a la verdad», sería un movimiento hacia atrás; pero Amelia replica: «No es así, mi querido, no es así en absoluto: todo es un caos, nada tiene ni pies ni cabeza. Los caminos no existen. Y es mejor que vayas poniendo los platos. [...] ¿Y si el muerto no fuera el final, sino el principio de todos los problemas?». En la vida no ocurre como en las novelas policiacas: «La vida es puro azar, querido mío, y la muerte juega a los dados». Y añade restándole valor al crimen: «Lo importante es qué sucedió con toda esa pobre gente que se quedó viva, qué les pasó después. Lo fundamental no es la solución de los grandes enigmas, sino la vida de todos los días. Y no te quedes ahí pasmado». El cuento - situado en el centro de todos los relatos, de lo que sería la novela - aporta las claves estratégicas para la comprensión del conjunto: «Todo está a la vista, pero nadie lo ve», « ¿quién sabe cuántas cosas más pueden haber pasado en ese día [del crimen], y que no salieron en el periódico? ¿Por qué tienen que ser justamente esas las importantes? ¿Quién lo decide?» (126-127). Asî que entre réplica y contrarréplica se nos ofrece una doble visión o interpretación de la realidad: ¿qué es realmente lo importante? ¿qué es lo pequeño e insignificante?; también una guía de lectura para el lector, que es múltiple: ¿debemos seguir un orden o la lógica de la causalidad? ¿o abandonarnos al azar o al caos, pues los caminos no existen? También se plantean las preguntas de la vida ante la realidad de la muerte: buscar la verdad (el detective) o buscar la felicidad y la vida (Amelia).

En La muerte juega a los dados encontramos ingredientes de inspiración borgiana, que funcionan a su vez como elementos vinculantes de una literatura y otra, en el vasto mundo de las intertextualidades. Entre muchas alusiones y guiños a otras obras, queremos destacar significativas coincidencias intertextuales con el relato borgiano de Ficciones, «Examen de la obra de Herbert 
Quain», en que el escritor protagonista Herbert Quain resume los ingredientes de su propia obra literaria, The God of the Labyrinth:

Hay un asesinato en las páginas iniciales, una lenta discusión en las intermedias, una solución en las últimas. Ya aclarado el enigma, hay un párrafo largo y retrospectivo que contiene esta frase: Todos creyeron que el encuentro de los dos jugadores de ajedrez había sido casual. Esta frase deja entender que la solución es errónea. El lector, inquieto, revisa los capítulos pertinentes y descubre otra solución, que es la verdadera. El lector de ese libro singular es más perspicaz que el detective (Borges 1944: 52).

Así mismo, el lector debe transformarse en detective el entramado de los cuentos si quiere aceptar la propuesta de juego y seguir y perseguir las pistas que van de la unidad a la totalidad, en esa estructura del relato de conjunto, el relato de relatos de La muerte juega a los dados que coincide asombrosamente con la de la obra de Quain. Clara Obligado juega a la invención de una obra heterodoxa, construyendo, además, —según la poética narrativa Quain, en April March - una «novela regresiva, ramificada», en la que cada ramificación tiene un carácter distinto, en la que «todo lo sacrifica a un furor simétrico» en relatos desiguales, donde «la yuxtaposición les presta eficacia»; evocando un mundo «en que la muerte precede al nacimiento y la cicatriz a la herida y la herida al golpe», como afirma Quain de su propia obra (Borges 1944: 52, 54). Clara Obligado, tras el sendero borgiano - subrayando que lectura y escritura se emulsionan en un mismo proceso de creación - coincide con Quain, el escritor-personaje de Ficciones, cuando «afirmaba también que de las diversas felicidades que puede ministrar la literatura, la más alta era la invención» (Borges, 1944: 55); quizá así el juego de la literatura nos distraiga de tener que jugar con la muerte, con el tiempo, con el olvido.

La muerte precede al nacimiento y trunca los destinos y plantea preguntas a lo largo de la obra, a partir de la del patriarca Héctor Lejárrega del primer cuento. Reaparece con recursividad en otros relatos como asunto fundamental representado en el destino de varios personajes. En «El cuerpo» (cuento número 3), Alma (única hija de Leonora, segunda generación) convertida en una anciana, trata de recordar, pero apenas puede bucear en sus recuerdos mezclando verdades ignoradas y algún secreto inconfesado. Recuerda muy en el pasado, otra muerte, anterior a la del padre, la muerte de Viv, su alma gemela de la infancia, cuando aparece ahogada en la pileta donde se bañaban y jugaban en verano. La imagen que perdura en su memoria se asemeja a la de una nueva Ofelia, una imagen que realmente no existió pero ocupa un lugar de la memoria indubitable. Como señala Alonso Benito, el hecho biográfico no es un hecho positivo sino algo que permanece como argumento cognitivo, y es en mitad de esa distancia que hay entre uno y otro donde se resuelve como reelaboración del lenguaje y de la enunciación (1998: 71). Como lo recuerda Alma:

No podía ser verdad, ya que ella no había vista la escena, pero estaba segura de que, cuando la sacaron del agua, la niña tenía la boca llena de flores. Flores salidas quién sabe de dónde, porque en el agua no hay flores, y el pelo derramado como una medusa. Ese recuerdo la acompañaba desde muy pequeña. Mucho antes de ser esta vieja que está en una silla mirando pasar las nubes, antes de que la abandonara su marido, antes de que nacieran sus hijas, antes de que le probaran el vestido de novia, antes de quitarse por última vez el uniforme oscuro del colegio de monjas, antes de cruzar la plaza abrazada a sus cuadernos, antes de que muriera su padre (31). 
El movimiento hacia atrás de la rememoración, el giro en espiral hacia el origen devuelve la mirada de la anciana hasta su niñez, dibujando con emoción una breve curva que abarca toda su vida. No es solo la nostalgia, el dolor persiste tan inmarcesible como la imagen y reconvierte el viejo tópico clásico del Ubi sunt en un enérgico reproche a los responsables de esa muerte:

\footnotetext{
Volvió a acercarse al ataúd y, aunque allí no había pasado nada triste, las sombras bailarinas de las velas dibujaban un revoloteo de fantasmas. Alma quiso buscarla dentro de sí mismo, se concentró en la luz de su cabeza pero no logró atravesarla, el espíritu tembloroso de Viv había huido. ¿Qué hacían todos esos adultos ahora, rodeando un cuerpo vacío? ¿Qué hacían, venerando una cáscara? ¿Dónde estaban cuando la niña se lanzó a correr hacia la pileta, cuando creyó que su reflejo era una muñeca, cuando pensó que el agua era un espejo sobre el que se podía caminar? ¿Dónde estaban cuando tuvo miedo, cuando manoteó desesperada, cuando empezó a gritar, cuando se anegaron sus pulmones? ¿Dónde estaban siempre los adultos? Si Viv es una inocente, se dijo Alma, alguien tiene que ser culpable.

Se había terminado el verano y, para inscribirse en el nuevo colegio, Alma tuvo que sacar su primer documento de identidad. En la foto, que tomó la policía, tiene unas ojeras profundas y una firma infantil estampada sobre un lugar y una fecha que, de todos modos, ella nunca olvidará («El cuerpo», 45).
}

La experiencia traumática de la muerte es por sí misma una frontera: marca un antes y un después en la vida de Alma que desde entonces comienza a tener pequeños desvanecimientos. Un lugar y una fecha quedan registrados en el documento de identidad que firmó aquel día, pero todavía y también en su memoria frágil la imagen ligada a la atmósfera de final del verano y a una herida que se repite en el tiempo. En el acontecer de la vida, los hechos parecen repetirse y parecen inevitables, ineluctables, pero no lo son con toda su exactitud. La casualidad, el azar - como en muchos de sus cuentostrastornan la idea de una vida predeterminada. Es como si hubiera un cálculo (lo que pretende O’Brian) y luego un error de cálculo (la vida, según Amelia). Y el punto final no es fijo. Hay que mirar en todas direcciones: hacia el pasado, encontraremos la nostalgia del mundo perdido, la crueldad de algunos acontecimientos; hacia el futuro, una incertidumbre o una mirada esperanzada. Los caminos se multiplican, se bifurcan como en un laberinto. ¿Existirá alguno que conduzca a una vida feliz?

\section{La palabra que ordena el caos: poiesis}

La literatura, había dicho H. Quain, puede procurar diversas felicidades y la más alta es la de la invención. Gracias a la creación poética y a la sintaxis de la escritura es posible reunir los fragmentos de una realidad fracturada y restañar las heridas del tiempo. Porque, si «la verdadera patria es el idioma», como es para Clara Obligado, cierta forma de regreso, de vuelta a casa desde el exilio, es posible en la palabra poética. La importancia de esto se ve bien en la historia del conde polaco Edmund («Porcelana»), que emigra a Buenos Aires a mediados del siglo XX, cuando los rusos le desposeen de todo, de su patria, de su infancia, incluso del idioma:

Pero él era un poeta. ¿Y cómo podría vivir sin las palabras? No hay nada en el mundo más triste que un poeta sin idioma, pensó y, en ese momento de extrema lucidez, comprendió por fin la magnitud de su desgracia (186).

Edmund quería ser poeta, pero ahora, en el exilio, es un poeta sin palabras, que recuerda la época feliz en que tenía un idioma, y que duda entre suicidarse o aprender de una vez el castellano. En otro 
relato, su hijo, en una nueva bifurcación del destino, vuelve a Polonia para poner bajo tierra, su tierra polaca, el «libro de sonetos perfectos» que su padre había terminado por escribir y publicar en Argentina. El poeta sin palabras del exilio, adoptando un nuevo idioma, cumple así inesperadamente un feliz destino en su patria.

Las palabras no solo se quedan huérfanas, también atesoran el poder transformador de la realidad y muchos personajes manifiestan de forma recurrente esa capacidad de admirarse o de sorprenderse ante ellas, rebosando ironía y humor. Rayja, la vecina lapona de Fernanda, pone un cartel en la puerta de su casa que dice «Rayja, taumaturga», pues —como ella dice- una médium taumaturga es como decir «adivina, pero más fino porque se parece a "traumatóloga"» (139). Con sentido positivo, se registra el asombro ante las palabras de algunos personajes como Fernanda, sensible a sus connotaciones, frente a los que son sordos a sus matices: «Me gustan las plantas, y las palabras que las rodean. Pecíolo o folíolo, tan esdrújulas, esporas y su promesa adherente y erótica, estolones, marcial como un ejército, ¡soldados estolones en ristre! Pero mamá es monofásica con el idioma, [...] así que enseguida se aburre de mis juegos de palabras. En realidad, no me aguanta, ni yo a ella». Como se ve, las palabras también sirven para marcar las filias y fobias de los personajes. Pero también para manipular o camuflar la cruda realidad, a veces con un esfuerzo eufemístico no exento de crueldad: a Alma nunca la reñían «porque había perdido a su padre, aunque nadie puede perder un padre como si fuera un calcetín. Perdido quería decir muerto, y un padre muerto es siempre un buen salvoconducto» (39). En el último cuento, su protagonista recuerda la primera vez que soñó con su hermana Sonia, sometida a tortura:

La primera vez fue cuando desapareció, aunque decir «desapareció» convierte la barbarie en el truco de un ilusionista. Entonces vos y yo (en este recuerdo no podría decir «tú y yo», cómo se solapan los castellanos, imposible encontrar una lengua que lo abarque todo) tú y yo nos tuvimos que exiliar (213).

La patria es el idioma (otros también lo han dicho), pero el idioma es aquí también un lugar de frontera, una escritura mestiza y bifurcada ${ }^{7}$. No solo en cuanto al uso del castellano, que es deliberadamente híbrido y alterna en sus variantes diatópicas, sino porque, además, aparecen por las páginas de los relatos otros idiomas «descentrados» (polaco, hebreo...), fuera de su contexto habitual, pero dentro de pasajes importantes en la trama.

El idioma es la herida, la escisión, pero también la memoria y la cura: «Salimos de la brutalidad a través de la belleza», leemos en la historia de Teo, titulada «Nada útil». Un cuento poético y metapoético que nos habla de la (in)utilidad de la belleza. En el dormitorio de un pequeño apartamento de cortinas de seda amarilla, en el barrio judío de Le Marais, se esconde Teo de los soldados alemanes. Mientras espera tenso la inminente captura, escucha la voz de su madre siempre amonestándolo por su actitud soñadora «No sabes hacer nada útil». Escucha en el escondrijo el batir de la mariposa en el

\footnotetext{
${ }^{7}$ Andrés Newman habla de la "escucha bifurcada" que trata de conciliar dos formas idiomáticas en una sola: «La escritura procede de la perplejidad ante la lengua materna. Es como si mi oreja derecha escuchase un lugar del idioma, la oreja izquierda otro y mi boca tratase de conciliar las percepciones de ambas. [...] Hoy ya no soy capaz de pensar en castellano sin sospechar de mi propio léxico, sin someter simultáneamente todo lo que digo a una escucha bifurcada» (2017).
} 
cristal, encuentra un libro japonés que es un tratado de geometría oriental (es el bello libro japonés que Gastón le regalara a Leonora con el que aprendió a hacer pajaritas para vaciar su mente), recuerda el jardín de manzanos de su casa... siente miedo al escuchar las voces alemanas...recuerda a Marie... Teo se entretiene con los pliegues del papel, desea replegarse también, barrer el tiempo..., hace y deshace, «los pliegues del papel tienen memoria...», recuerda el verano, las manzanas..., a su madre...Se le está acabando el papel y tiene una fila de pajaritas de distintos tamaños...(«nunca suficientes», le diría Leonora a su hija Alma en otro tiempo) solo le queda el del hermoso libro; se acercan los soldados, ... siente miedo, vergüenza, arrepentimiento a los ojos de la madre. Dos miedos, el de la madre, el de los soldados... No tiene papel y cada vez hay más gritos en la calle... La gente: «a ver cómo se lo llevan, seguro que era judío...». Cuando están a punto de prenderle, al abrirse la puerta, la explosión de «pajaritas furiosas...». Basta ese segundo de desconcierto para que Teo corra hacia la ventana, atraviese las cortinas amarillas... ¡salta por la ventana!, desesperado y libre, hacia el jardín de las manzanas... Es una historia de liberación a través de la belleza y de lo aparentemente inútil. Nunca son suficientes, le dice Leonora a su hija mientras le enseña a hacer la pajarita de papel: «-Para tener suerte, hay que hacer mil. — ¿Y para qué sirven? — Para nada, mi amor, las cosas bellas nunca sirven para nada» (15).

En relato posterior, en ese mismo apartamento vive Fernanda, de nuevo con Bruno, bastante feliz en el París de antes de la guerra, y no renuncia a la nostalgia de la quinta de «Los naranjos» en Buenos Aires. Ha encontrado una pajarita en papel japonés. En el mismo apartamento, mucho tiempo después, se reúne con ella la escritora, el personaje que cierra el último de los cuentos del libro, «Verano», cuyo título adquiere, en la clausura del relato, el valor de ser la estación de la escritura y de la felicidad serena. «Verano» es el relato personal de una escritora que, desde el pueblecito francés de Maintenon, a 22 kilómetros de París, está escribiendo un libro con el que, tras la muerte de su madre, ajusta cuentas con su pasado, «lo más parecido a una autobiografía», confiesa en primera persona la voz narradora.

En simetría especular, frente a la muerte del patriarca que abre el libro, encontramos esta vez la muerte de Alma (que es la hija de la viuda del patriarca, Leonora, y la madre de Sonia -que desapareció- y las mellizas de la tercera generación) cerrando este fractal narrativo. La escritora le dirige a su hermana que vive en Inglaterra una carta en la que le da cuenta de las últimas horas de vida de su madre. De paso, de forma subrepticia, se desvela ante el lector precavido un secreto que resiste en la frágil memoria de una víctima de Alzheimer: se ha roto el tabú de esa muerte, la novela policiaca se cierra, pero transformada en un relato más íntimo dentro del género epistolar. La narradora evoca desde el presente su recuerdo de las dos hermanas hablando de una cama a otra en la casa de «Los naranjos» en Buenos Aires («iTe acuerdas de nuestros veranos?»). Recuerda los veranos de la infancia en los que todavía estaba Sonia; constata cómo sus vidas se han distanciado mientras siguen paralelas (una en Inglaterra, otra en Madrid); ambas se casaron, ambas tuvieron hijos; ambas fueron profesoras. «Historias simétricas, de gemelas»—concluye—, «Yo me separé. Vos no. Siempre he sido un caos...» (213). Y continúa volviendo a un pasado que se repite: 
Sos la melliza exitosa, yo la que avanza a trompicones. Querida hermana, ¿no sientes que todo sigue sucediendo? ¿Que Sonia, desde algún sitio misterioso, no puede cesar de gritar? Sobre el horizonte la luz sanguinolenta del alba ilumina la catedral. Es mejor que intente dormir (214).

Era Sonia la que siempre leía y la que quería ser escritora, pero es una de sus hermanas la que cumple ese destino en este último relato narrado en un presente relativamente feliz (como también es el tiempo de la narración de otras situaciones límite, como el relato de Sonia torturada en la jaula de los Gritos, en el cuento de «Las eléctricas», el de Teo y sus pajaritas, en «Nada útil», o el de Fernanda feliz con Bruno en Buenos Aires). Desde del presente de este último relato, la escritora siente que, en realidad, las cosas no terminan de dejar de pasar, que todo se está repitiendo y que Sonia, la otra hermana desaparecida, no puede cesar de gritar (2015a: 214). «Los hechos más graves están fuera del tiempo», pues «el pasado inmediato queda como tronchado del porvernir», «porque no parecen consecutivas las partes que los forman» —expresa J. L. Borges en el cuento de «Emma Zunz» (1949: 167)—, en un presente que es factual y atemporal para siempre. Es ahí donde surge la necesidad y la última razón de la escritura:

Quizá uno inventa ficciones para darle sentido a los naufragios. Recuerdo el día en que empecé a escribir este libro, que pronto daré por concluido. Fue poco después de la muerte de mamá, estaba sola en Buenos Aires, sentada en Clásica y Moderna, desayunando [...]. Así empecé con este libro, que es lo más parecido a una autobiografía que, de momento, soy capaz de redactar: yo señores, en posesión de la verdad. Yo señores, narrándome. Mis recuerdos son la argamasa con la que levanté estos muros. Pero, a medida que voy avanzando, me doy cuenta de que todo lo que cuento es cierto, menos la mayoría de los hechos. ¡Es tan frágil la memoria! Tan mentirosa. Dicho de otro modo, los hechos no son exactos, las consecuencias, sí. [...] ¿Escribo, como Proust, para atrapar el tiempo perdido? [...] Esta semana he terminado casi diez páginas que me convencen, ya te pasaré el manuscrito para que me des tu opinión, te va a divertir reconocer la historia de nuestra familia convertida en cuentos (218-220).

En este último relato se ofrece, por tanto, el origen de la escritura como una especie de exorcismo de los demonios familiares, de la pérdida irreparable de la infancia y del trauma de la muerte, con toda la impronta proustiana impregnando la argamasa de los recuerdos, para construir un tercer nivel en esta armazón narrativa: no solo es la historia de un crimen, ni la saga de tres generaciones a través de las otras vidas olvidadas - especialmente, pero no solo, de las mujeres - de quienes rodearon al patriarca; es también la historia personal de quien la escribe, una autobiografía donde «los hechos no son exactos, las consecuencias sí» (219). Y que se escribe desde el «ahora» y en ese ahora es «verano».

«Y ahora yo», se dice a sí misma la narradora ante su propio destino. «Verano» plantea una recuperación del tiempo perdido que justifica el conjunto de los relatos anteriores, desvela alguna verdad que estaba latente, confiere serenidad a una historia traumática, se cumple en él el destino de convertirse en escritora. Aunque esta no tiene el nombre de nuestra autora (consideremos una forma de autoficción anónima o innominada), descubrimos en el personaje afinidades: su posición de mujer extranjera, en la vieja Europa, viajando por Francia - aunque no está en París (como fuera el sueño literario de tantos exiliados argentinos) sino en su periferia, "excéntrica"-, buscando jardines de un lugar a otro, mientras trata de rescatar el pasado y reescribirlo, volver atrás, reconfigurando un universo poético útil para el momento presente. 
«Siempre es invierno en la historia de mi vida» había dicho Fernanda, pero «el tiempo lo invierte todo» y ahora, para ella también es verano, según observa la escritora desde la perspectiva final del relato, desde la actualidad de su presente. Fernanda, desde la mejor época de su vida, alternando su vida entre Buenos Aires y París, en ese apartamento de Le Marais, es la expresión de una posibilidad de felicidad:

Me gusta encontrarme con ella, es la única de la familia que ha sabido vivir con inteligencia. En cuanto la recuerdo me veo susurrando mi propia oración laica: "Bienaventurados los felices, porque de ellos será la sabiduría”. ¿O será al revés? ¿Bienaventurados los sabios, porque de ellos será la felicidad? Tía Fernanda abre la puerta y me abraza con todo el cuerpo, sabes que odio los abrazos, pero a ella se lo permito. Sigue en esa casa preciosa que heredó de su padre, ¿la recuerdas?, en Le Marais, con sus cortinas de seda amarillas, pero ha cambiado los muebles por otros modernos, livianos. Ah, las cortinas, se asombra, cuando las elogio, ¡qué memoria! Claro que no son las mismas, claro que estas son nuevas. Quería que algo quedara igual, el alma de las casas, ya sabes. Mira lo que he encontrado. Y me muestra una pajarita hecha con un papel bellísimo, con caracteres japoneses (214-215).

«Verano» es «la estación de la escritura»y en ella se supera el dilema que se planteaban el detective O’Brian y Amelia su esposa: buscar la verdad o buscar la felicidad. Como en el poema de "Los justos” de J. L. Borges, descubrimos una etimología: «Maintenon» no es un lugar en el espacio cerca de París, sino que es, jugando con el sonido de la palabra, un 'ahora', un punto en el tiempo, una de sus bifurcaciones posibles, entre el pasado y el futuro, en el que la búsqueda de la belleza y de la creación poética mediante la escritura puede recomponer (e inventar) y dar un sentido nuevo a un mundo fragmentado. En «Verano», entre visitas a la casa de Proust en Illers-Combray la escritora se pregunta el sentido de escribir: «¿Escribimos para atrapar el tiempo? ¿Sobre la vida que pudo ser y no fue? ¿La que no nos atrevimos a llevar a cabo? ¿Frotamos una lámpara maravillosa y salen de allí nuestros recuerdos? (209). La escritura recupera el tiempo... «porque el papel tiene memoria», como decía Teo, pero también nos recupera a nosotros mismos al permitirnos un ajuste con nuestro propio pasado, recortarlo, replegarlo para volverlo a desplegar como un papel y construir una bella figura de origami, con el breve lienzo en que transcurre nuestra vida. Y también recupera alguna forma de verdad: como dice Walter Benjamin, «articular históricamente el pasado no significa conocerlo tal y como verdaderamente ha sido. Significa adueñarse de un recuerdo tal y como relumbra en el instante de un peligro» (Alonso Benito 1998: 71).

Para Clara Obligado, «vivir es equivocarse», «pero podemos modificar nuestros errores» — sostiene también-, «podemos volver a pasar por nuestra vida, girar y enmendar nuestros errores» (2011c). Y reescribirnos, como afirma la escritora en el cuento de clausura: «Nada de lo que recordamos es verdad. Nada de lo que imaginamos es mentira» (2015a: 225). En el cruce entre la verdad y la imaginación, entre la fatalidad y la belleza, puede crear un universo cálido, diríamos feliz, en la estación de la escritura. Y puede que entonces sea el turno del lector, puede que recuerde en un movimiento regresivo, ese último cuento del libro anterior, Las otras vidas, y a su protagonista autoficcional, en su viaje al exilio, ese 5 de diciembre de 1976, en que llega a Madrid «aterida de frío», porque «venía del verano»y «la tristeza y la falta de sol fueron el primer impacto». 


\section{Escribir o cultivar un jardín}

Escribir es atrapar el tiempo, reescribirse imaginando nuevos caminos y senderos como posibilidades azarosas de un destino no siempre terrible. La narradora última de «Verano» los recorre, mientras atraviesa bosques y campos de trigo por Francia, buscando jardines, imaginando que abandona la literatura para dedicarse a las plantas: «no se me ocurre nada más placentero que cultivar un jardín» (210). Conecta así con un ideal de vida epicúreo, y volteriano, con el que el ilustrado concluye su Cándido: un consejo para conseguir una vida razonablemente feliz, en un mundo que quizá no sea el mejor de los mundos posibles. En este último relato de «Verano» no se trata de un único jardín, de un jardín particular o un «hortus conclusus», sino de múltiples y diversos jardines diseminados por la geografía. La búsqueda y el descubrimiento de nuevos jardines (¿quizá otra tarea inútil?) llevan a la escritora a desplazarse de un lugar a otro, fuera de su patria, a cruzarse con otros destinos, como el de Kamil, un emigrante sin palabras y sin tierra (como lo era Edmund, el poeta polaco), con el que juega a los dados, que no es más que un sueño de su imaginación, o ese destino fatal al que el último de los personajes también se enfrenta. El plural hace pensar en jardines más bien borgianos, de senderos que se bifurcan, de espacios y tiempos transitados por la vida de los otros, «las otras vidas» posibles. . Las palabras también viajan y desplazan la imaginación del lector de un lugar a otro con su poder de alusión. También hace pensar en "El jardín del exilio" (como en el Museo del Holocausto de Berlín), erigido para la memoria y el recuerdo de los desterrados.

En su vagar entre pueblos, la protagonista de «Verano» encuentra a un anciano que cuida de un jardín medieval, que «está muy cuidado, emociona»:

El jardín tiene una zona umbría, jalonada por bancos de piedra para la meditación, otra con hortalizas, hierbas medicinales y el boj, que simboliza la eternidad: todo sucede entre el cielo y esta tierra. Definitivamente, debería dejar la escritura para dedicarme a las plantas. ¿No es, en el fondo, lo mismo? (21617).

Escribir, cuidar de un jardín... De nuevo las palabras funcionan como vínculos entre las ramificaciones intertextuales desplegadas en los textos de Clara Obligado, que trata de conectarlos con las de otros autores, construyendo una red, un tejido poético que supera los límites de su creación propia, dejándonos ver una imagen fractal más amplia, que va del detalle al conjunto, de su libro a otros libros, a la literatura global y universal. Aquí, en «Verano», volvemos a descubrir «un jardín de senderos que se bifurcan», húmedo y zigzagueante, como en el relato de Borges, en el que se accedía a una biblioteca de libros orientales y occidentales, que - recordemos - estaban encuadernados en seda amarilla (Borges, 1944: 69). Como en este, Clara Obligado nos ha llevado por «un laberinto de marfil», «un laberinto de símbolos», «un invisible laberinto de tiempo»y, ahora, descubrimos que la escritora quiere cerrar su relato en la actitud de Ts'ui Pên, el docto astrólogo, ajedrecista, famoso poeta y calígrafo del relato de Borges, que «todo lo abandonó para componer un libro y un laberinto», como si de dos cosas distintas se tratara. Solo su descendiente Yu Tsun descubrió que uno y otro eran una misma cosa: el jardín de senderos que se bifurcan era la novela caótica. «La confusión de la novela me sugirió que ese era el laberinto», revela: 
Me detuve, como es natural en la frase: «Dejo a los varios porvenires (no a todos) mi jardín de senderos que se bifurcan». Casi en el acto comprendí; el jardín de senderos que se bifurcan era la novela caótica; la frase varios porvenires (no a todos) me sugirió la imagen de la bifurcación en el tiempo, no en el espacio. La relectura general de la obra confirmó esa teoría. En todas las ficciones, cada vez que un hombre se enfrenta con diversas alternativas, opta por una y elimina las otras; en la del casi inextricable Ts'ui Pên, opta - simultáneamente- por todas. Crea, así, diversos porvenires, diversos tiempos, que también proliferan y se bifurcan (Borges, 1944: 71).

En el tejido borgiano y en la obra de Obligado, el jardín y la escritura son la misma cosa, y la cuidada composición del libro que el lector sostiene es un laberinto ordenado que emociona: en él se dan cita la novela policiaca, los preliminares de un crimen, el ajedrez, las bifurcaciones del tiempo... y los diversos destinos. Clara Obligado construye, crea, su propio laberinto poético, sus propios senderos, y lo puebla con los posibles destinos y porvenires de personajes (Leonora, Alma, Sonia, las mellizas...), y objetos (copas de cristal, mariposas, figuras de origami...) que son, finalmente, desde la lectura final del último de los relatos, no una secuencia de fatalidades sino quizá posibilidades azarosas y no excluyentes de una misma vida, como en el libro-jardín de Ts'ui Pên. Dentro del caos construye un orden de belleza, que es su propio jardín, su propio universo, a veces absurdo a veces lógico, a menudo cruel, siempre impregnado de belleza: en uno de esos caminos, en uno de esos tiempos divergentes, convergentes o paralelos, hay un destino que se cumple poética y felizmente en la escritura.

$\mathrm{Si}$, como recordábamos al principio, para Séneca «todo el tiempo que andamos dando vueltas de un lado para otro, no tras de un guía [...] [y] en direcciones opuestas, la vida se_desgasta entre divagaciones, breve, aunque nos esforcemos en mejorar día y noche. De modo que hay que decidir a dónde nos dirigimos y por dónde...», en la poética de Obligado, no existe una sola dirección, ni existe un solo camino para la felicidad. Más bien, con Ana $\mathrm{M}^{\mathrm{a}}$ Shua, siente que para buscarla hay que internarse en un jardín de senderos bifurcados y, siguiendo el proverbio chino, en la encrucijada dividirse, o quizá también, elegir y perderse ${ }^{8}$.

La opción definitiva por la escritura le permite a Clara Obligado salvar la encrucijada. «Todo pasa más allá de las palabras» es una frase ambigua y fronteriza que resuena en el último relato: al mismo tiempo que afirma la fugacidad de las cosas, el paso de los años, la pérdida de la infancia, la muerte..., declara en su reverso el poder de rescatar los mundos perdidos o de redimir un pasado hostil, cuando se combinan poiéticamente e inventan una belleza extrañada, imprevisible, azarosa, como lo hace Clara Obligado, fiel a su destino de escritora. Jardín o laberinto, a mitad de camino entre el caos y la fatalidad, existe una forma de «felicidad escrita», una felicidad extraviada y reencontrada como posibilidad en el giro de la fortuna, en cada vínculo con las otras vidas, otros espacios, otros idiomas y otras literaturas, en una mirada excéntrica, desde su condición de exiliada y extranjera, hacia lo que está fuera del marco y apenas se ve, reescribiendo el pasado desde el presente, imaginando ficciones

\footnotetext{
${ }^{8}$ «Si nunca me extravié en el jardín de los senderos que se bifurcan es porque fui fiel al antiguo proverbio que exige: en la encrucijada, divídete. Sin embargo, a veces me pregunto, la felicidad, ¿no es elegir y perderse?» (2009: 636).
} 
dentro de un orden matemático, buscando la verdad y la vida en la atemporal belleza de la mímesis poética, ese lugar de senderos bifurcados para perderse y ser felices.

\section{Bibliografía}

AlCANTAR, Stephanie (2017): «Redefiniendo los límites del lenguaje. Un estudio sobre la aplicación de conceptos matemáticos en la literatura hispanoamericana», Vernacular, New Connections in Language, Literature, \& Culture, Vol. 2, Article 3; en http://trace.tennessee.edu/vernacular/vol2/ iss1/3/ (última consulta, 9-VII-2017).

AlONSO BENITO, Luis Enrique (1998): La mirada cualitativa en sociología: una aproximación interpretativa. Madrid, Fundamentos.

AlOnso Monedero, Begoña (2013): «Metaficción con una esquina rota: sobre "Exilio" de Clara Obligado», en M. Cots, P. GIFRA y G. HAMBROOK, eds., Interrogating Gazes / Miradas interrogantes. Comparative Critical Views on the Representation of Foreignness and Otherness. Berna, Peter Lang, pp. 317-324.

BARTHES, Roland (1993): «Semántica del objeto», en La aventura semiológica. Trad. Ramón Alcalde. Barcelona, Paidós, $2^{\mathrm{a}}$ ed., pp. 245-55.

BorgeS, Jorge Luis (1944): Ficciones, en Borges esencial. Madrid, Real Academia Española Asociación de Academias de la Lengua Española, 2017, pp. 7-128.

(1949): El Aleph, en Borges esencial. Madrid, Real Academia Española - Asociación de Academias de la Lengua Española, 2017, pp. 129-240.

_ (1994): El idioma de los argentinos. Buenos Aires, Seix Barral. (2005): Arte poética. Seis conferencias. Barcelona, Crítica, $2^{a}$. ed., 2010.

CoDoÑEr, Carmen, ed. (1986): Séneca, Lucio Anneo, Diálogos. Madrid, Tecnos.

NEUMAN, Andrés (2017): Blog Microrréplicas; en http://andresneuman.blogspot.com.es/2015/01/ escucha-bifurcada-y-2.html (última consulta, 9-VII-2017).

NOGUEROL JIMÉNEZ, Francisca (2008): «Juntos, pero no revueltos: la colección de cuentos integrados en las literaturas hispánicas», en Vicente CERVERA y María Dolores ADSUAR, eds., Alma América. Homenaje a Victorino Polo. Murcia, EDINUM, vol. 2, pp. 162-172.

OBLigAdo, Clara (2004): «La creación de textos mínimos», en Francisca NoGUEROL JiMÉNEZ, ed., Escritos disconformes. Nuevos modelos de lectura. Salamanca, Universidad de Salamanca, pp. 335-344.

- (2005): Las otras vidas. Madrid. Páginas de Espuma.

- (2006): «La palabra patria es machista y de derechas. ¡Me quedo con matria!», Culturas, 2-15 de marzo de 2006, p. 5.

- (2011a): El libro de los viajes equivocados. Madrid, Páginas de Espuma. (2011b): «La escritura al margen», La jornada semanal, 832; en http://www.jornada.unam.mx/

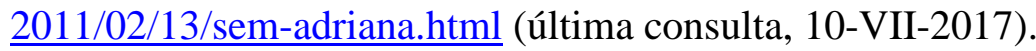


110 Tropelías. Revista de Teoría de la Literatura y Literatura Comparada, 30 (2018) Begoña Alonso Monedero

(2011c): «Mis personajes rezan a un mamut y luego se lo comen», El Mundo, 1 de diciembre de 2011; en http://www.elmundo.es/elmundo/2011/11/30/cultura/1322669018.html (última consulta, 10-VII-2017)

(2015a): La muerte juega a los dados. Madrid, Páginas de Espuma.

(2015b): «La escritora argentina afincada en España Clara Obligado presenta su nuevo libro en la Biblioteca de Huelva», Huelva Buenas noticias, 19 de marzo de 2015; en http://huelvabuenasnoticias.com/2015/03/19/la-escritora-argentina-afincada-en-espana-claraobligado-presenta-su-nuevo-libro-en-la-biblioteca-de-huelva/ (última consulta, 10-VII-2017).

SHuA, Ana Ma (2009): Cazadores de letras. Minificción reunida. Madrid, Páginas de Espuma.

ZAVALA, Lauro (2000): «Seis problemas para la minificción, un género del tercer milenio: Brevedad, Diversidad, Complicidad, Fractalidad, Fugacidad, Virtualidad». El Cuento en Red: Estudios sobre la Ficción Breve, 1, pp. 17-26. 